Article DOI: https://doi.org/10.35219/im.2018.1.05

\title{
PARAMETRIC MODELING DRUM USED TO AMT 125 AUTO CRANE
}

\author{
PhD. Gina Diana MUSC $\breve{A}$ (ANGHELACHE) \\ "Dunărea de Jos" University of Galați, \\ Engineering Faculty of Brăila, \\ Research Center for Mechanics of Machines \\ and Technological Equipment
}

\begin{abstract}
This paper presents a modern design parametrized method using the NX 7.5 modelling software. This software is a complete high-tech software integrated CAD/ CAM/ CAE, produced by SIEMENS PLM company. For the preparation of this paper I modelled drum AMT $125 T$ crane. I started with the description of the drum and then I made a presentation of the stages of $3 D$ modelling on a drum, also presenting the graphic images of those stages.
\end{abstract}

KEYWORDS: Drum, 3D modelling, parametric design, CAD

\section{INTRODUCTION}

The drum for driving cables and chains is used for lifting equipment of the cranes, to trolleys and conveyors.

When lifting, lowering and moving the freight, due the torque a tangential peripheral force is generated, which opposes the effort of the flexible body due to the freight.

Single or double drums variants are used for the lifting equipment.

In general, the drum has a cylindrical shape, also using the truncated cone drum, in some cases.

High lifting heights, to avoid large lengths, the drum is allowed to wind the cable in several layers, leading to a decrease in the operating cable durability.

In this case, the drum used is smooth, with high margins with a size equal approx. twice the diameter of the cable.

Usually, the drums are built grooved, with a trench after a cylindrical helix (the groove elements being standardized), so that the neighbouring windings turns should not rub each other [1].

Grooving also increases the contact surface of the cable drum, thus lowering the pressure contact between the cable and the drum, leading to increased cable durability.
The drum calculation is:

The main dimensions of the cable drums diameter, wall thickness and active length. At the grooved drums for the cables, the groove is helical and has the dimensions:

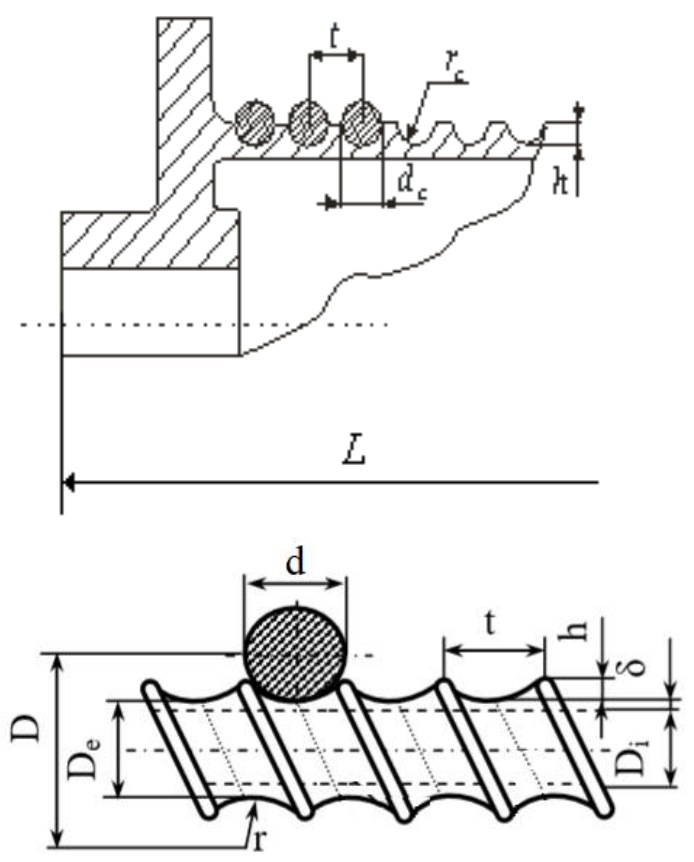

Fig. 1.1. The elements of the drum 
The elements of the grooved drum are: $\mathrm{t}$ - step of the groove; $\mathrm{r}$ - radius of curvature of the groove; $d$ - diameter of cable; $h$ - the height of the grooves; D - average diameter; $\mathrm{D}_{\mathrm{e}}$ - external diameter; $\mathrm{D}_{\mathrm{i}}$ - inside diameter.

Drum diameter:

$$
\mathrm{D} \geq \mathrm{d}_{\mathrm{c}} \cdot\left(\mathrm{e}_{1} \cdot \mathrm{e}_{2}-1\right)
$$

Where: $\mathrm{e}_{1}$-coefficient that takes into account the type of car; $\mathrm{e}_{2}$ - coefficient the takes into account the action mode; $\mathrm{e}_{1}=$; $\mathrm{e}_{2}=28$

The length of the drum:

$$
l_{\text {inf }}=H \cdot n
$$

Where: H-lift height; n-number of active branches

On the drum wraps a helical groove. The step of a helical groove:

$$
t=d+(2 \ldots 3)
$$
cable:

The number of active coils that wrap the

$$
n_{a}=\frac{l_{\text {inf }}}{\pi \cdot D}
$$

Drum length:

$$
L=\left(n_{a}+7\right) \cdot t
$$

Followed by checking relationship:

$$
\frac{L}{D}-1 \ldots 1,5
$$

The drums are made of welding or cast steel. They are also made of cast iron, constructive solution, more homogeneous, stronger and heavier weight. On operation, the drums are being stressed by torsion, bending and compression. The most important of these demands is the compression [5].

For the long drums a verification on bending is required.

The coils of both the cables and chains that wrap the drum sit evenly side by side, being carefully arranged to avoid overlapping.

If the ropes and the chains are not calibrated, then smooth drums are used, while for calibrated chains, grooved drums are used. For the cables wrapped of a single line the drums will be grooves, and for the cables wrapped in several rows the drums will be smooth [8].
There are three types of drums: drums for chains, drums for textile cables and drums for metallic cables.

\section{3D MODELING FOR THE DRUMS OF AMT125 AUTOCRANE}

In the following I will model a drum for steel cables.

This drum is often used in the operation of hoists and is made of cast steel, steel sheet or steel tubes welded at both ends [3].

These drums have the mantle provided with helicoid grooves for cable and for a better settlement of the winding cable on the drum. So, turns are intended to be regular and evenly wound on the drum.

To achieve the parametric modelling and applied technological operations used to the drum of the AMT125 auto crane, we used the design NX 7.5 software from Siemens PLM.

This is a fully integrated CAD/ CAM / CAE software. In the CAD module is made the 3D model of the products [4]. To achieve the 3D model for the drums of the auto crane we used the application named modelling which builds the solid models 3D parametric.

\section{Steps towards achieving the $3 D$ model of the drum:}

The first step is to create a sketch, which is a combination of $2 \mathrm{D}$ dimensional elements (lines, circles, arcs), which can be established by hard relations.

Through these relationships the model profile can be controlled. The operation that we have created on the basis of drawings is associative; it follows that, if we change the design, the operations will automatically change [7].

We created the sketch on the XY plane, then I realized the half axial section of the drawing drum Mirror Curve later command, which I mirrored half of an axial section of the drum (Fig. 2.1).

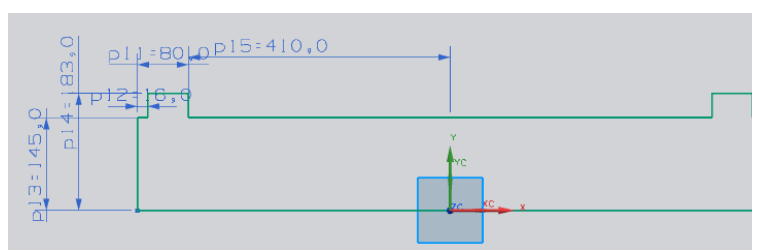

Fig. 2.1. Axial section of the drum

In the second stage, we have created a solid body of the drum Revolve command (Insert-Feature-Design-Revolve) which can perform various tasks by turning a curve, 
faces, sketches or edges of a face around a specified axis (Fig. 2.2).

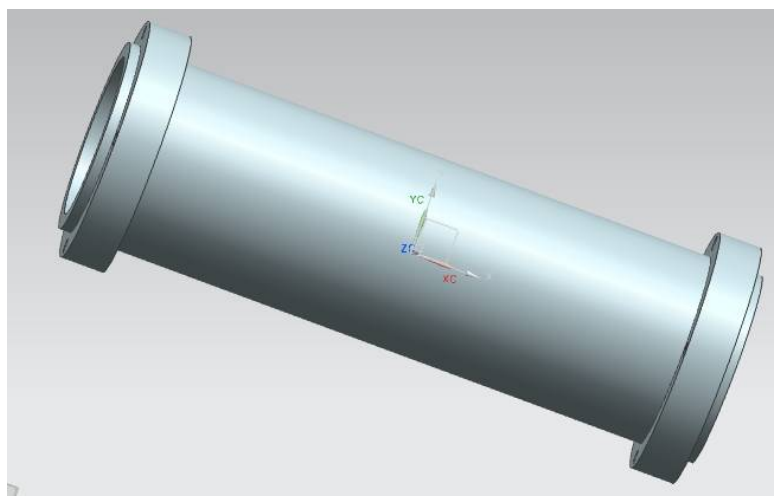

Fig. 2.2. Drum body

The third stage was to achieve axial section of the drum.

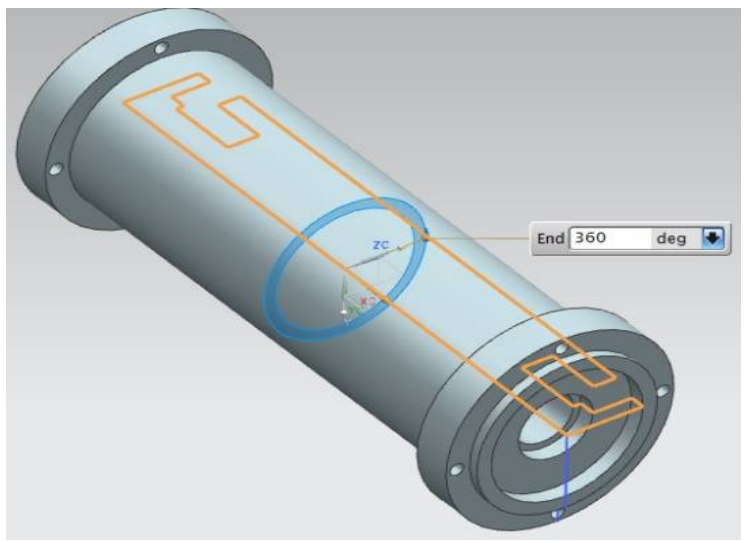

Fig. 2.3. Axial section of the drum

The first step was to create a sketch on the XY plane where the outline of the axial section of inner drum is realized, and after the drawing we use the command Revolve, like in the previous operation, except the list of Booleans we opted for Subtract (Fig. 2.3)

During the fourth stage, we created threads winding the cable.

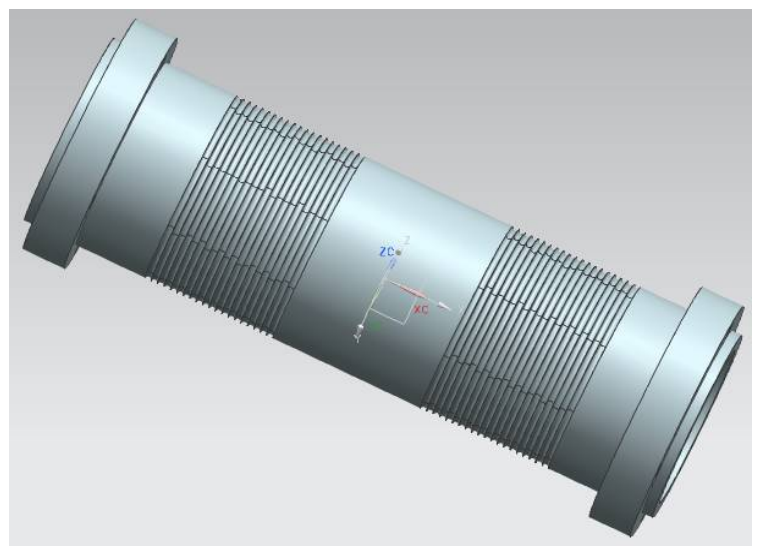

Fig. 2.4. Inserting threads
We first created the turns using Helix command, then with the Tube command we created a circular volume on each spiral and then we extruded them, using the Subtract command (Fig. 2.4).

In the last stage, we created the holes on the front surface of the drum [8].

First, we created a sketch on the front surface of the drum, and realized the 4 holes fair, then I made another sketch whole front surface of the drum, and I realized the other 4 equidistant holes, subsequently using Extrude command, I realized the 3D model of drilling drum. The last step was to create the outline on the front surface of the drum and after we finished sketch 3D model, using the Extrude command (Fig. 2.5).

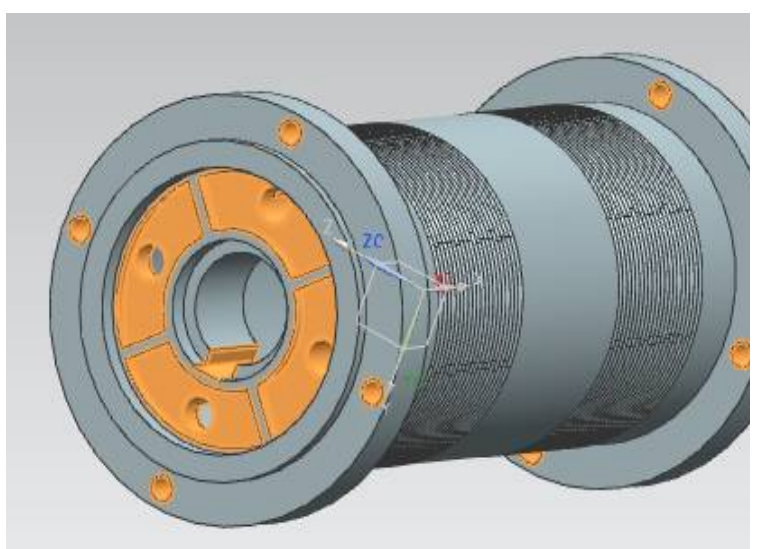

Fig. 2.5. 3D drum model

Figure 2.6 shows a double model drum 3D mode, using the NX 7.5 software.

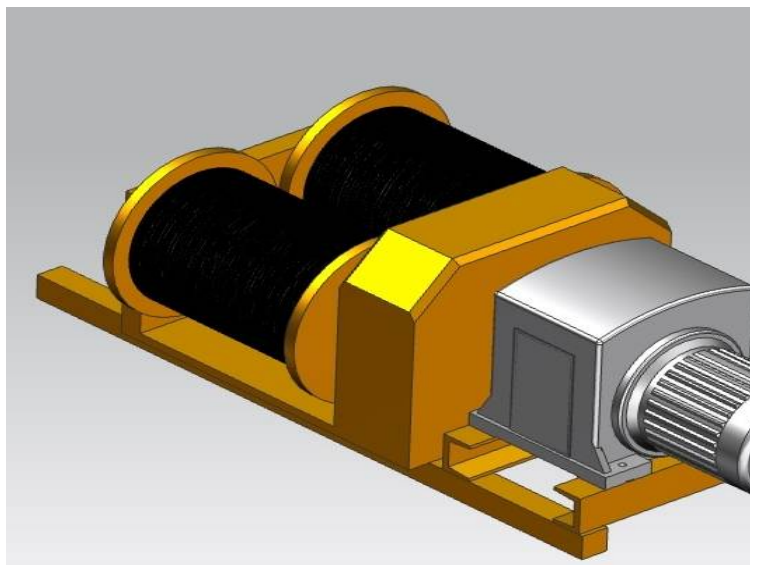

Fig. 2.6. 3D model of double drum

\section{CONCLUSIONS}

The present paper presents a modern method of parametrized design of a piece from the AMT 125T auto crane, namely the winding cable drum of the load lifting. 
The $3 \mathrm{D}$ modelling is effective in creating drum types and sizes in a very short time, at the same time achieving 2D drawings automatically and adapting them to changes with the $3 \mathrm{D}$ model. as:

Parametric modelling offers such benefits

- Starting from simple conceptual models, with minimal details, this approach complies the philosophy design "form before dimension".

Follow the applying dimensional geometric constraints and parametric equations that can be used for capturing lens design (design intent).

- The possibility of rapid exploitation and evaluation of various alternative design options and to determine the best solution.

\section{REFERENCES}

[1] Alămoreanu, M., Coman, L., Nicolescu, Ş., Lifting machines, Vol. 1, Technical Publishing House, Bucharest, 1996.

[2] Boteanu, N., Lifting and transportation facilities, Universitaria Publishing House Craiova, 2012.

[3] Goanță, A. M., Complex system of modern informatics methods for teaching graphics disciplines from technical field, International Conference on Engineering Graphics and Design, ICEG, 200.

[4] Goanță, A. M., Ghelase, D., Dașchievici, L., Graphic results of applying CAD tools to design automotive braking systems, Proceedings of the 9th WSEAS international conference on System science and simulation in engineering, 2010.
Existing data can be reused in other projects.

Although simple to use, this interface allows the use of advanced features when needed and customization through modularity.

Besides the usual customizing toolbars, NX can be adapted to user requirements and to the use of roles. Another advantage that $3 \mathrm{D}$ model offers is kind CAE simulation analysis (Computational Analysis Element) and see the exactly tension and deformations of the piece.

And last but not least, with the help of the 3D model programs such as CAM (Computational Aided Machining) can be created to automate manufacturing of special pieces in production.

[5] Oproescu, G., Machines and installations for industrial transport, Edmunt Publishing House, 2001, Brăila.

[6] Potîrniche, A., Căpățână, G., Finite element analysis of an excavator bucket embedding ripper teeth, The Annals of "Dunărea de Jos" University of Galați, Fascicle XIV Mechanical Engineering, ISSN 1224-5615, 2009.

[7] Potîrniche, A., Căpățână, G., Computational assessements regarding modal analysis of an elevator bucket. The Annals of "Dunărea de Jos" University of Galați, Fascicle XIV Mechanical Engineering, ISSN 1224-5615, 2009.

[8] Vâță, I, et al. - Lifting machines for construction. Exploitation, maintenance, repairs, Technical Publishing House, Bucharest, 1989. 